\title{
EDUCAÇÃO PARA GESTÃO AMBIENTAL: UM ESTUDO DOS INSTRUMENTOS PROPOSTOS PELA ADMINISTRAÇÃO PÚBLICA FEDERAL VOLTADOS AO CONSUMO SUSTENTÁVEL
}

Evangelina da Silva Sousa ${ }^{1}$

Denis Barros de Carvalho ${ }^{2}$

Resumo: O objetivo desta pesquisa é apresentar iniciativas desenvolvidas por instituições públicas federais visando à adoção de práticas sustentáveis em suas atividades, por meio de suas compras públicas. Foi realizada pesquisa documental com enfoque exploratório, junto ao portal de compras do Governo Federal, para coletar os dados. Os resultados mostram que as compras sustentáveis são instrumento para mudança nos padrões de consumo, cabendo à Administração Pública implementar ferramentas, por meio do processo de sensibilização e conscientização dos seus agentes sobre 0 paradigma ambiental.

Palavras-chave: Educação ambiental. Compra Sustentável. Universidade.

${ }^{1}$ Universidade Federal do Piauí. E-mail: evangelinasousa@ufpi.edu.br

${ }^{2}$ Universidade Federal do Piauí. E-mail: denispsi@bol.com.br 


\section{Introdução}

Diante da globalização dos problemas ambientais, faz-se necessário que as organizações públicas e privadas adotem uma postura social e ambientalmente responsável, relacionando suas estratégias competitivas com o conceito de desenvolvimento sustentável, definido pela Comissão Mundial de Meio Ambiente e Desenvolvimento (1991:46), como "aquele que atende às necessidades do presente sem comprometer a possibilidade de as gerações futuras atenderem a suas próprias necessidades".

A partir da formulação do conceito de desenvolvimento sustentável, a questão ambiental tem abordagem estratégica, uma vez que deve garantir condições de vida para as futuras gerações, pois "implica assumir 0 compromisso com a perenização da vida ao horizonte da intervenção e da transformação da natureza pelo ser humano" (SIMÕES, 2008: 90).

Se faz mister que, a preocupação com a sustentabilidade provoque mudanças de valores nas organizações e requeira nova percepção ambiental, por meio da prática da responsabilidade social que consiste na "relação ética e transparente da organização com todas as suas partes interessadas, visando o desenvolvimento sustentável' (ABNT, 2004: 3).

Os problemas ambientais requerem do Estado à incorporação de práticas ambientais em suas políticas públicas, por meio de instrumentos de gestão ambiental criados para atingir os efeitos ambientais benéficos (BARBIERI, 2011).

Portanto, para assegurar uma gestão pública ambiental eficaz, é necessário que os órgãos públicos desenvolvam ferramentas que minimizem os impactos ambientais, além de gerenciar, efetivamente, as entidades por intermédio da criação de parâmetros de sustentabilidade ambiental, por meio da tomada de decisão.

Uma das ferramentas que pode contribuir para 0 alcance do desenvolvimento sustentável, por meio das organizações governamentais, é a implementação de contratações sustentáveis, uma vez que a Administração Pública tem a capacidade para influenciar as relações econômicas (ISLAM, 2013), sendo a maior consumidora de bens e serviços no mercado brasileiro, movimentando cerca de $10 \%$ do Produto Interno Bruto (SANTOS, 2010).

Percebendo a importância do Estado como agente econômico, e que suas atividades provocam impactos na economia, mudança de atitudes de seus gestores juntamente com aprovação de políticas públicas ambientais estimulariam novas contratações sob a perspectiva ambiental.

A construção de uma nova cultura organizacional pública, voltada para a inserção de critérios sociais e ambientais em sua rotina administrativa, acarretará em um diferencial estratégico, no qual os agentes públicos, por meio da mudança de valores e práticas, se transformarão em novos atores e contribuirão para um meio ambiente mais equilibrado. 
Considerando a relevância do paradigma da sustentabilidade voltado para o consumo, o objetivo desse trabalho é apresentar iniciativas, propostas por instituições públicas federais, no intuito de demonstrar a aplicabilidade das compras sustentáveis, e como essas aquisições podem contemplar o conceito de sustentabilidade ambiental, uma vez que compete ao poder público estimular a adoção de novos padrões de consumo e produção, por meio da educação ambiental podendo fazê-lo por meio de suas compras.

O trabalho está organizado em quatro seções, além da introdução, na próxima apresentam-se as orientações metodológicas. Na terceira seção, temse a base teórica sobre educação e gestão ambiental no setor público e consumo sustentável, enquanto na quarta, destacam-se as principais iniciativas da Administração Pública Federal e na última as considerações finais.

\section{Procedimentos metodológicos}

A trajetória metodológica desta pesquisa iniciou com a seleção de referencial teórico, para revisão de literatura, priorizando os trabalhos com enfoque voltado para educação e gestão ambiental, além de direcionar o consumo sustentável para a esfera pública, explorando algumas iniciativas praticadas pela Administração Pública Federal.

A pesquisa é de cunho qualitativo e possui caráter exploratório, tendo em vista que permitirá conhecer com maior profundidade a temática pesquisada, uma vez que é pouco explorada (GIL, 2009), tratando-se, também, de um estudo descritivo, pois faz um delineamento de manuais voltados a contratações públicas sustentáveis e de experiências vivenciadas por instituições públicas federais.

\section{Revisão da literatura}

O objetivo dessa revisão consiste em apresentar conceitos da educação ambiental e das compras públicas sustentáveis, assim como a fundamentação legal que legitima a inserção de critérios ambientais nas licitações em busca do consumo sustentável.

\section{Educação Ambiental}

A crise ambiental é resultante de problemas de conhecimento e suscita implicações para a política ambiental e a educação, posto que devam ser incorporados valores a percepção que se tem sobre o mundo. Aprender a conhecer a complexidade ambiental acarretará na captação de novos saberes e transformação do conhecimento e de práticas educativas para a construção de um mundo sustentável (LEFF, 2010).

Tem-se a educação como instrumento de mobilização para a aprendizagem, no qual o individuo desenvolve novos saberes, sendo capaz de 
se inter-relacionar social e ecologicamente, para que as gerações futuras possam usufruir de um meio ambiente equilibrado.

Em 1999, foi instituída Política Nacional de Educação Ambiental, por meio da Lei Federal no 9.795, que em seu art. 1ํ define Educação Ambiental (EA) como:

os processos por meio dos quais o indivíduo e a coletividade constroem valores sociais, conhecimentos, habilidades, atitudes e competências voltadas para a conservação do meio ambiente, bem de uso comum do povo, essencial à sadia qualidade de vida e sua sustentabilidade. (BRASIL, 1999).

Conforme preconiza 0 art. $3^{\text {a }}$ da lei $n^{0}$ 9.795/99, compete ao poder público desenvolver políticas públicas que promovam a educação ambiental no processo educativo, além de engajar a sociedade na conservação e melhoria do meio ambiente.

De acordo com Pelicioni e Philippi Jr (2005) a educação ambiental prepara os cidadãos para a reflexão crítica e uma ação social corretiva ou transformadora, de maneira que seja possível o desenvolvimento dos seres humanos. Logo, a educação ambiental é um processo de aprendizagem permanente que converte o ser humano em um agente de transformação, uma vez que promove a mudança de sua postura e atitude perante o meio ambiente, visando à minimização dos impactos ambientais provocados pela ação antrópica.

Para Vargas (2010), a educação ambiental exige a ampliação da participação do cidadão como ator político, em busca da solução para os problemas ambientais, pautada em valores éticos, sociais e políticos.

Seiffert (2011) considera a educação ambiental um instrumento de gestão ambiental, embora sua aplicabilidade esteja condicionada à implantação de políticas públicas educacionais que proporcionem a mudança cultural e comportamental da sociedade.

A educação é essencial para o alcance do desenvolvimento sustentável, já que envolve a mudança dos padrões de consumo, cultura e valores, despertando a consciência ecológica para a valorização da natureza. A educação ambiental está associada ao exercício da cidadania e à reformulação de valores éticos e morais para a transformação humana, em busca da preservação ambiental, uma vez que deve focar a interdisciplinaridade entre o homem e a natureza. 


\section{Compra pública sustentável no cenário brasileiro}

As compras públicas estimulam a competitividade empresarial, uma vez que para dar continuidade às suas atividades a Administração Pública requer fornecedores que consigam suprir a contento suas necessidades, nos ditames legais, assim, o governo assume o papel de garantidor de demanda para empresas privadas, contribuindo para sua permanência e desenvolvimento no mercado (MOREIRA; VARGAS, 2009).

O processo de compras nas instituições governamentais obedece a procedimentos formais que envolvem o cumprimento da legislação pertinente às aquisições públicas, por meio da licitação, um procedimento administrativo no qual se seleciona a proposta mais vantajosa para a Administração, a fim de que os recursos públicos sejam despendidos da forma mais adequada obedecendo aos princípios constitucionais, garantindo condições de igualdade aos interessados e a promoção do desenvolvimento sustentável, conforme preconiza o art. $3^{\circ}$ da lei ํㅡ 8.666/1993.

A expressão "desenvolvimento nacional sustentável" foi incluída com a Lei oㅜ 12.349/2010, que alterou a Lei ํo 8.666/1993 (Lei de Licitações e Contratos Administrativos), e infere a possibilidade da inserção de critérios ambientais nas licitações públicas para que seja alcançada a sustentabilidade, e por meio da inserção de critérios ambientais, sociais e econômicos, a licitação cumpre sua função social, uma vez que esta pode se sobrepor aos interesses administrativo, financeiro e técnico como critérios de avaliação. (FERREIRA, 2012).

Silva, Balbino e Gómez (2011) apontam que é de responsabilidade do Estado a regulamentação e a fiscalização de atividades que proporcionem o alcance do desenvolvimento sustentável. Para tanto, o Governo Federal, por meio da Instrução Normativa ${ }^{\circ}$ 01/2010 dispôs sobre a inserção de critérios de sustentabilidade ambiental na aquisição de bens, contratação de serviços ou obras pela Administração Pública Federal direta, autárquica e fundacional, formalizando a adoção desses critérios nas licitações públicas, uma vez que os valores economicistas orientavam na seleção da proposta mais vantajosa para a Administração.

Desta forma, surge o termo compra e/ou licitação sustentável que consiste na valorização dos custos efetivos de longo prazo, considerando critérios sustentáveis de consumo, em busca de benefícios à sociedade e ao meio ambiente nas licitações (MENEGUZZI, 2011).

Walker et al (2009) reitera que as licitações sustentáveis devem integrar os critérios ambientais, sociais e econômicos durante o processo aquisitivo, para que o setor público satisfaça suas necessidades de forma sustentável.

Porém, para a efetiva implementação das Compras Públicas Sustentáveis (CPS), é necessário conhecer as fases para inclusão dos critérios ambientais, sociais ou éticos que são: especificação do produto, definição do 
documento de bases e condições particulares e avaliação, seleção e adjudicação dos ofertantes (SANTOS, 2010).

No que concerne à metodologia para implementação das CPS, a etapa mais importante refere-se ao mapeamento do perfil de consumo da instituição, onde será executado um planejamento das compras que serão realizadas, para que possam ser definidos, posteriormente, os critérios de sustentabilidade para tais aquisições, como abordagem e análise do ciclo de vida, valoração ambiental e desenvolvimento tecnológico.

Santos (2010) expõe que as principais barreiras para implementação das compras públicas sustentáveis são desconhecimento ou incentivos que impulsionem a mudança de comportamento. Gunther e Scheibe (2004) afirmam que os principais obstáculos para implementação das CPS são falta de: conhecimento, incentivos, informação, legislação, regulamentos e sistemas de sanções.

Porém, as compras sustentáveis são amparadas pela fundamentação legal, elencada no Quadro 1 (próxima página), que torna o procedimento legítimo e tal arcabouço ampara os servidores envolvidos no processo de aquisição das instituições públicas, garantindo o cumprimento dos princípios constitucionais da legalidade e segurança jurídica, cumprindo o disposto no art. 225 da Carta Magna, ao garantir à sociedade um meio ambiente equilibrado preservando-o para as intergerações.

Santos (2010) afirma que antes das Leis № 12.187/09 (institui a Política Nacional sobre Mudança Climática); no 12.305/10 (institui a Política Nacional de Resíduos Sólidos) e no 12.349/10 (introduziu como objetivo da licitação a promoção do desenvolvimento nacional sustentável), não havia norma expressa que obrigasse o Estado brasileiro a priorizar a aquisição de bens ou a contratação de obras e serviços por meio das licitações sustentáveis.

Embora existam normas que regulamentem as contratações sustentáveis, é importante destacar que a escolha do objeto a ser licitado é discricionária, ou seja, depende da conveniência e da oportunidade do agente público que deve conhecer os critérios ambientais a serem incluídos no edital de licitação, para que se efetive uma aquisição e/ou contratação sustentável. Com isso,

pretende-se demonstrar que o poder normativo da Administração deve ser utilizado para fornecer parâmetros à discricionariedade dos gestores públicos durante a escolha dos bens, obras e serviços a serem contratados, pautando essa limitação na defesa do meio ambiente, de acordo com as disposições constantes no ordenamento jurídico brasileiro (SANTOS, 2011, p.158). 
Quadro 1: Fundamentação legal das Contratações Públicas Sustentáveis.

\begin{tabular}{|c|c|}
\hline Instrumento Legal & Objeto \\
\hline Constituição Federal de 1988 & $\begin{array}{l}\text { Em seu art. } 225 \text { estabelece a proteção ao meio ambiente e retrata o princípio } \\
\text { do desenvolvimento sustentável }\end{array}$ \\
\hline Lei no 8.666/1993 & $\begin{array}{l}\text { Institui normas para licitações e contratos da Administração Pública e dá } \\
\text { outras providências. }\end{array}$ \\
\hline Resolução CONAMA no 20/1994 & $\begin{array}{l}\text { Dispõe sobre a instituição do Selo Ruído de uso obrigatório para aparelhos } \\
\text { eletrodomésticos que geram ruído no seu funcionamento. }\end{array}$ \\
\hline Lei no 9.605/1998 & $\begin{array}{l}\text { Dispõe sobre as sanções penais e administrativas derivadas de condutas e } \\
\text { atividades lesivas ao meio ambiente. (Lei de crimes ambientais). }\end{array}$ \\
\hline Decreto $n^{\circ} 2.783 / 1998$ & $\begin{array}{l}\text { Dispõe sobre a proibição de aquisição de produtos ou equipamentos que } \\
\text { contenham ou façam uso das substâncias que destroem a camada de ozônio } \\
\text { - SDO pelos órgãos e pelas entidades da Administração Pública Federal } \\
\text { direta, autárquica e fundacional. }\end{array}$ \\
\hline Lei no 10.257/2001 & $\begin{array}{l}\text { Regulamenta os arts. } 182 \text { e } 183 \text { da Constituição Federal e estabelece as } \\
\text { diretrizes gerais da política urbana, dentre as quais a adoção de proteção e } \\
\text { consumo de bens e serviços de expansão urbana compatíveis com os limites } \\
\text { da sustentabilidade ambiental, social e econômica do Município e do Território } \\
\text { sob sua área de influencia. }\end{array}$ \\
\hline $\begin{array}{l}\text { Resolução CONAMA no } \\
\text { 307/2002 }\end{array}$ & $\begin{array}{l}\text { Estabelece critérios e procedimentos para gestão de resíduos na construção } \\
\text { civil. }\end{array}$ \\
\hline Decreto $n^{\circ} 4.131 / 2002$ & $\begin{array}{l}\text { Dispõe sobre medidas emergenciais de redução do consumo de energia } \\
\text { elétrica. }\end{array}$ \\
\hline Decreto n $5.940 / 2006$ & $\begin{array}{l}\text { Disciplina a separação dos resíduos recicláveis descartados pelos órgãos e } \\
\text { entidades da administração pública federal direta e indireta, na fonte geradora, } \\
\text { e a sua destinação às associações e cooperativas dos catadores de materiais } \\
\text { recicláveis. }\end{array}$ \\
\hline Portaria do MMA nº 61/2008 & $\begin{array}{l}\text { Estabelece práticas de sustentabilidade ambiental quando das compras } \\
\text { públicas sustentáveis. }\end{array}$ \\
\hline Portaria do MMA no $43 / 2009$ & $\begin{array}{l}\text { Proíbe o uso do amianto em obras públicas e veículos de todos os órgãos } \\
\text { vinculados à Administração Pública. }\end{array}$ \\
\hline Lei no $12.187 / 2009$ & $\begin{array}{l}\text { Instituiu a Política Nacional sobre Mudança de Clima (PNMC), que tem como } \\
\text { uma de suas diretrizes o estímulo e o apoio à manutenção e à promoção de } \\
\text { padrões sustentáveis de produção e consumo (art.5o, XIII), e como um de } \\
\text { seus instrumentos a adoção de critérios de preferencia nas licitações e } \\
\text { concorrências públicas para as propostas que propiciem maior economia de } \\
\text { energia, água e outros recursos naturais e redução da emissão de gases de } \\
\text { efeito estufa e de resíduos (art, } 6^{\circ}, \text { XII). }\end{array}$ \\
\hline Decreto $\mathrm{n} \times \mathbf{0} 7.174 / 2010$ & Regulamenta a contratação de bens e serviços de informática e automação. \\
\hline $\begin{array}{l}\text { Instrução Normativa do MPOG - } \\
\text { SLTI n0 01/2010 }\end{array}$ & $\begin{array}{l}\text { Dispõe sobre os critérios de sustentabilidade ambiental na aquisição de bens, } \\
\text { contratação de serviços ou obras pela Administração Pública Federal. }\end{array}$ \\
\hline $\begin{array}{l}\text { Portaria do MPOG - SLTI no- } \\
02 / 2010\end{array}$ & $\begin{array}{l}\text { Regulamenta a compra de tecnologia da informação com critérios ambientais } \\
\text { de sustentabilidade. }\end{array}$ \\
\hline Lei no $12.305 / 2010$ & $\begin{array}{l}\text { Instituiu a Política Nacional de Resíduos Sólidos (PNRS), cujo art. } 7^{\circ} \text {, inciso } \\
\mathrm{XI} \text {, destaca como um dos objetivos a prioridade nas aquisições e contratações } \\
\text { governamentais de produtos reciclados e recicláveis, assim como de bens, } \\
\text { serviços e obras que considerem critérios compatíveis com padrões de } \\
\text { consumo social e ambientalmente sustentáveis. }\end{array}$ \\
\hline $\begin{array}{l}\text { Medida Provisória ํㅜ 495/2010, } \\
\text { convertida na Lei nº 12.349/2010 }\end{array}$ & $\begin{array}{l}\text { Incluiu como finalidade da licitação a promoção do desenvolvimento nacional } \\
\text { sustentável. Esse normativo definiu como não comprometedores ou não } \\
\text { restritivos da competitividade das licitações vários dispositivos incluídos no art. } \\
\left.3^{\circ} \text { da Lei } n^{\circ} 8.666 / 93 \text { ( } \S \S 5^{\circ} \text { ao } 12^{\circ}\right) \text {, muitos voltados à proteção à indústria e } \\
\text { produção locais, dentre os quais, o } \S 5^{\circ} \text {, que autoriza o estabelecimento de } \\
\text { margem de preferencia para produtos manufaturados e serviços nacionais } \\
\text { que atendem a normas técnicas brasileiras. }\end{array}$ \\
\hline Lei $\mathrm{n}^{0} 12.462 / 2011$ & Institui o Regime Diferenciado de Contratações, dentre outras disposições. \\
\hline Decreto $n^{\circ}$ 7.746/2012 & $\begin{array}{l}\text { Regulamenta o artigo } 3^{\circ} \text { da Lei } 8.666 / 93 \text {, agregando como objetivo da Lei de } \\
\text { licitações e contratos, o desenvolvimento nacional sustentável. }\end{array}$ \\
\hline
\end{tabular}


Então, os critérios de escolhas dos agentes públicos devem se pautar no ordenamento jurídico, considerando a redução dos impactos ambientais e maior benefício à sociedade, mesmo que tais escolhas impliquem em um maior custo de aquisição.

Segundo Betiol et al. (2012), o grande entrave para a realização de licitações sustentáveis refere-se à especificação dos itens a serem adquiridos, pela falta de conhecimento ao definir os critérios ambientais e do engajamento dos servidores no processo, pois alegam que as compras sustentáveis restringem a competitividade e possuem um preço elevado comparado aos produtos tradicionais, indo de encontro com a Lei no 8.666/1993.

Pelo princípio da economicidade, entende-se que a proposta mais vantajosa é aquela que possui o menor valor de aquisição, ou seja, a compra é vista de forma imediatista, desconsiderando, assim, os custos de uso e manutenção dessas aquisições, que implicam na economia dos recursos naturais (menor consumo de água e energia elétrica) e na redução dos impactos ambientais.

Barcessat (2010) corrobora que as contratações sustentáveis atendem ao princípio da economicidade, uma vez que o eventual aumento dos custos dos produtos e/ou serviços é nivelado, a médio e longo prazo, pela redução dos danos ambientais, na qual a adoção da variável ambiental nas aquisições públicas proporciona uma visão mais sustentável e menos financeira nos procedimentos licitatórios.

Assim, ratifica-se que a proposta mais vantajosa para a Administração Pública não é aquela que possui o menor valor de aquisição, mas a que atende aos requisitos mínimos de qualidade necessários para o atendimento das necessidades identificadas, além de cumprir a função social de promoção do desenvolvimento sustentável (GUIMARÃES, 2012).

As aquisições sustentáveis estimulam a inovação, uma vez que os produtores alteram seu processo produtivo, pois "ao promoverem contratos ecológicos, as autoridades públicas podem dar à indústria verdadeiros incentivos para desenvolverem tecnologias ecológicas" (COMISSÃO EUROPEIA, 2005, p.5), além de proporcionar a criação de um "mercado verde", que fornecerá aos consumidores produtos sustentáveis a um preço justo.

\section{Apresentação dos resultados}

Nesta seção são apontadas algumas iniciativas que estimulam a implementação das compras sustentáveis, por meio de manuais voltados para esta prática e experiências vivenciadas nas instituições públicas federais. 


\section{Manuais para as compras públicas sustentáveis no âmbito da administração pública federal}

Para o desenvolvimento da pesquisa, foram analisados três manuais: Agenda Ambiental da Administração Pública (2009), Guia de compras públicas sustentáveis para Administração Federal (2010), Guia de inclusão de critérios de sustentabilidade nas contratações da Justiça do Trabalho (2012), uma vez que foram elaborados com o objetivo de auxiliar os gestores e agentes públicos a incluírem a responsabilidade socioambiental em suas atividades rotineiras, enfatizando a sustentabilidade ambiental no âmbito governamental.

\section{Agenda Ambiental da Administração Pública (A3P)}

O Governo Federal, por meio do Ministério do Meio Ambiente, desenvolveu o programa Agenda Ambiental na Administração Pública (A3P) que visa a mudança da cultura organizacional, das entidades públicas, com a inserção de critérios de responsabilidade socioambiental nas atividades administrativas para o alcance da sustentabilidade no âmbito econômico, social e ambiental e tem com o objetivo de incentivar os gestores públicos a incorporar princípios gestão socioambiental nas atividades rotineiras para que seja alcançada a economia dos recursos naturais e financeiros (CRESPO, MATOS e ABREU, 2009).

A A3P definiu 5 (cinco) eixos temáticos norteadores para consecução de seus objetivos em prol da execução de práticas sustentáveis, abordados no Quadro 2.

Quadro 2: Eixos temáticos da A3P.

\begin{tabular}{|c|l|}
\hline Eixo Temático & \multicolumn{1}{c|}{ Ações } \\
\hline $\begin{array}{c}\text { Uso racional dos } \\
\text { bens naturais e } \\
\text { bens públicos. }\end{array}$ & $\begin{array}{l}\text { Utilizar bens naturais e públicos com racionalidade e de forma econômica evitando } \\
\text { desperdício, uma vez que o modelo econômico é baseado em padrões de produção e } \\
\text { consumo insustentáveis. Engloba o uso racional de energia, água e madeira além do } \\
\text { consumo de papel, copos plásticos e outros materiais de expediente. }\end{array}$ \\
\hline $\begin{array}{c}\text { Gestão adequada } \\
\text { dos resíduos } \\
\text { gerados }\end{array}$ & $\begin{array}{l}\text { Passa pela adoção da política dos 5R's: Repensar, Reduzir, Reutilizar, Reciclar e } \\
\text { Recusar. Dessa forma deve-se primeiramente pensar em reduzir o consumo e } \\
\text { combater o desperdício para só então destinar o resíduo gerado corretamente. }\end{array}$ \\
\hline $\begin{array}{c}\text { Qualidade de vida } \\
\text { no ambiente de } \\
\text { trabalho }\end{array}$ & $\begin{array}{l}\text { Facilitar e satisfazer as necessidades do servidor ao desenvolver suas atividades na } \\
\text { organização através de ações para o desenvolvimento pessoal e profissional. }\end{array}$ \\
\hline $\begin{array}{c}\text { Sensibilização e } \\
\text { capacitação dos } \\
\text { servidores }\end{array}$ & $\begin{array}{l}\text { Criar e consolidar a consciência cidadã da responsabilidade socioambiental nos } \\
\text { servidores. O processo de capacitação contribui para o desenvolvimento de } \\
\text { competências institucionais e individuais fornecendo oportunidade para os servidores } \\
\text { desenvolverem atitudes para um melhor desempenho de suas atividades. }\end{array}$ \\
\hline $\begin{array}{c}\text { Licitações } \\
\text { sustentáveis }\end{array}$ & $\begin{array}{l}\text { Promoção de responsabilidade socioambiental da Administração Pública em suas } \\
\text { compras. As licitações sustentáveis são importantes não só para a conservação do } \\
\text { meio ambiente mas também apresentam uma melhor relação custo/benefício a médio } \\
\text { ou longo prazo quando comparadas às que se valem do critério de menor preço. }\end{array}$ \\
\hline
\end{tabular}

Fonte: Adaptado de Crespo, Matos e Abreu, 2009. 
É um programa de adesão voluntária, em que os gestores públicos programarão práticas sustentáveis em suas atividades, por meio da execução de ações baseadas nos eixos temáticos do programa, gerando economia através do menor custo-benefício para a Administração Pública, além de proporcionar a minimização dos impactos socioambientais.

Uma sugestão proposta pelo programa é adoção da política dos 5 R's, caracterizada na Figura 1, considerada o marco inicial para introdução de práticas ambientais no ambiente de trabalho, e consistem em:

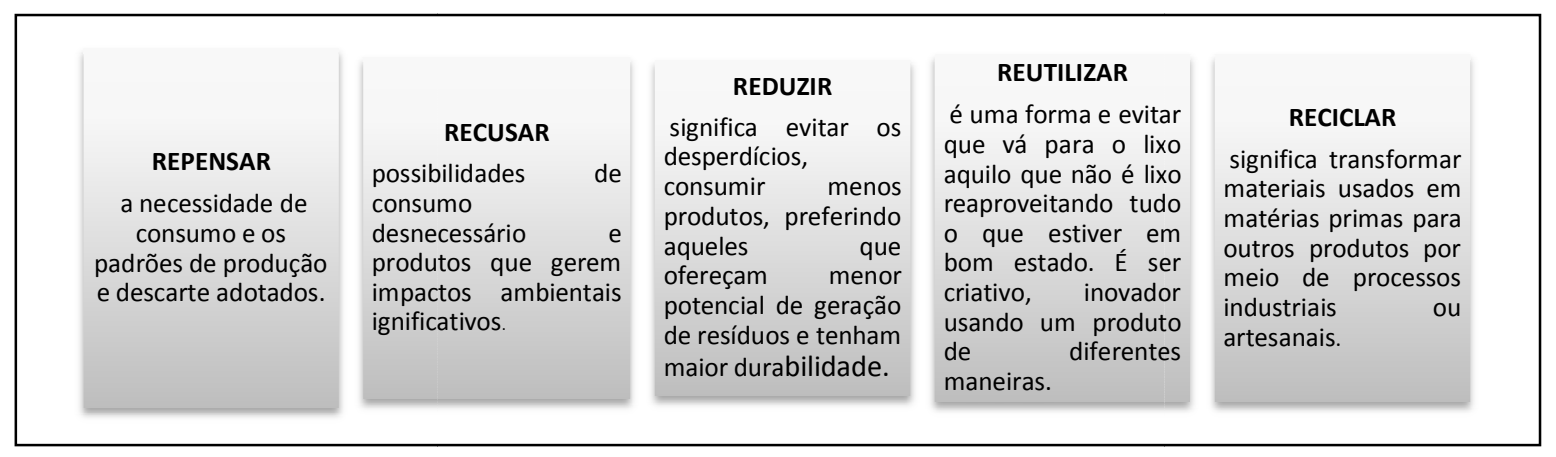

Figura 1: Princípios dos 5 R's. Fonte: Adaptado de Crespo, Matos e Abreu, 2009.

Portanto, para que as práticas ambientais sejam eficientes, eficazes e efetivas, faz-se necessário à implementação de um planejamento estratégico, a fim de que a organização pública desenvolva programas de educação ambiental voltados para aquisições e consumo sustentável, além de buscar a sensibilização dos seus colaboradores, para que os hábitos ambientais adquiridos com a capacitação sejam praticados em casa, uma vez que também são consumidores.

Vale ressaltar que a capacitação e o desenvolvimento profissional promovem um aprimoramento pessoal como parte da melhoria da qualidade de vida dos envolvidos, motivando-os a se tornarem agentes de mudança (CHIAVENATO, 2006).

É por meio do conhecimento que os consumidores obterão informações necessárias para a tomada de decisão que considere o consumo sustentável, uma vez que o ato de consumir é influenciado por fatores sociais e individuais, que afetam o processo de decisão de compra, salientando a importância do consumidor como ator de transformação, posto que possui o poder de decidir um padrão de desenvolvimento socialmente justo e ambientalmente equilibrado (FURRIELA, 2001).

Segundo Portilho (2005: 3), "as ações e as escolhas individuais 
essenciais", então, pode-se direcionar o consumo individual sustentável para as organizações empresariais (públicas e privadas), uma vez que os gestores detêm o poder de escolha e decisão, e tal escolha pode ser realizada com estratégias de compras que incluam a variável ambiental.

Assim, o consumo sustentável propõe a redução do consumo, além de exigir uma nova atuação do governo e sociedade em prol da coletividade, com a formulação de políticas públicas voltadas para a sustentabilidade.

\section{Federal}

Guia de compras públicas sustentáveis para Administração

Este manual foi idealizado pelo Ministério do Planejamento, Orçamento e Gestão em 2010, expõe o panorama, os benefícios e as ferramentas para implementação das compras públicas sustentáveis, além de apresentar os aspectos jurídicos e institucionais das aquisições verdes.

Apresenta algumas ferramentas ambientais que podem ser utilizadas no processo licitatório como: a abordagem do ciclo de vida que considera os impactos ambientais do produto em todas as etapas do seu ciclo de vida, a minimização das compras para reduzir os custos com aquisição, a certificação e a rotulagem ambiental que caracterizam o produto como sustentável e a valoração ambiental pois busca estabelecer o valor econômico de um recurso ambiental.

Por fim, o manual retrata que as compras públicas sustentáveis não contrariam a legislação vigente e baseiam-se em três preceitos: melhor relação custo-benefício (a proposta mais vantajosa não é aquela que apresenta menor valor de aquisição, mas a que observa critérios de qualidade, inclusive ambientais); contratação justa e isonômica (para que não haja beneficiamento de fornecedores, através da requisição de certificados ambientais restrito a um pequeno grupo de empresas) e transparência (os procedimentos de aquisição devem ser claros e objetivos).

\section{Guia de inclusão de critérios de sustentabilidade nas contratações da Justiça do Trabalho}

Diante da necessidade da adoção de novos padrões de produção e consumo e mediante a percepção do modo de vida insustentável do ser humano, o Conselho Superior da Justiça do Trabalho elaborou um guia para inclusão de critérios de sustentabilidade nas contratações realizadas pelos órgãos vinculados à Justiça do Trabalho.

O manual pretende "auxiliar e estimular o gestor a assumir uma atitude propositiva e investigatória, apontando caminhos possíveis com base na legislação e nas experiências vivenciadas" (BORGES, 2012, p.6). 
Para realização das contratações da Justiça do Trabalho, foram estabelecidas algumas diretrizes norteadoras para aquisições sustentáveis, quais sejam:

-Preferência por produtos de baixo impacto ambiental;

-Não geração, redução, reutilização, reciclagem e tratamento

dos resíduos sólidos, bem como disposição final ambientalmente adequada dos rejeitos;

-Preferência para produtos reciclados e recicláveis, bem como para bens, serviços e obras que considerem critérios compatíveis com padrões de consumo social e ambientalmente sustentáveis (Lei 12.305/2010);

-Aquisição de produtos e equipamentos duráveis, reparáveis e que possam ser aperfeiçoados;

-Adoção de procedimentos racionais quando da tomada de decisão de consumo, observando-se a necessidade, oportunidade e economicidade dos produtos a serem adquiridos;

- Nas aquisições e locações de imóveis, deve ser dada preferência a imóveis que atendam aos requisitos de acessibilidade previstos na NBR 9050 da ABNT, de forma a assegurar 0 direito de ir e vir das pessoas com deficiência e com mobilidade reduzida (BORGES, 2012, p.10-11).

Segundo Borges (2012), as contratações públicas sustentáveis representam a adequação da contratação ao consumo sustentável. Deve-se estimar o custo em sua amplitude, atentando para a manutenção dos recursos naturais e o bem-estar social.

Destaca-se a importância destes manuais, uma vez que orientam os agentes públicos sobre as medidas a serem adotadas para realização das licitações sustentáveis, esclarecendo os aspectos legais, sociais e ambientais, além de fomentar a discussão do consumo sustentável.

O consumo sustentável advém da mudança comportamental dos consumidores (individual/organizacional), convertendo-se em prática política, provocando inovações no mercado, uma vez que serão utilizadas novas tecnologias para produção de bens e/ou serviços sustentáveis.

\section{Experiências as Instituições Públicas Federais}

Entende-se que a inserção de critérios de sustentabilidade ambiental nas especificações de bens e serviços contratados pela Administração Pública Federal é possível, porém exige um esforço dos agentes públicos a fim de que entendam o paradigma da sustentabilidade, e esta proposta incentiva a educação ambiental. Assim, salienta-se a importância da criação de programas 
de formação continuada, uma vez que mudanças nos padrões de consumo são de responsabilidade do indivíduo.

Convém destacar que a compra pública sustentável é apenas uma iniciativa, que pode ser desenvolvida para que as instituições públicas insiram a sustentabilidade em sua gestão.

O Quadro 3 apresenta iniciativas de algumas instituições públicas federais que adotaram a sustentabilidade ambiental no processo de compras, a fim de que as práticas de gestão ambiental sejam incorporadas em busca do consumo sustentável.

Percebe-se que, embora as instituições pesquisadas realizem compras sustentáveis, suas práticas estão voltadas para a redução do consumo, e cabe destacar que apenas a Secretaria Geral da Presidência da República e o Ministério da Fazenda evidenciam a percepção e a educação ambiental com seus servidores, ao possuir um plano de capacitação e abordar a conscientização dos seus agentes, respectivamente, pois segundo Marin (2008) o homem não deve apenas ver o problema ambiental, mas vivenciá-lo de tal forma que desenvolva uma postura proativa mediante a questão e busque alternativas para ações de gestão da educação ambiental.

Quadro 3: Experiências de instituições públicas federais.

\begin{tabular}{|c|c|c|}
\hline Instituição e Iniciativa & Contexto & Resultados \\
\hline $\begin{array}{l}\text { Controladoria Geral da } \\
\text { União - Semana Verde } \\
\text { da Presidência da } \\
\text { República. }\end{array}$ & $\begin{array}{l}\text { Para a Coordenação de Almoxarifado e } \\
\text { Serviços de Patrimônio compras sustentáveis } \\
\text { se enquadram no uso racional dos recursos, } \\
\text { sejam humanos, financeiros ou naturais, de } \\
\text { tal forma que existam recursos disponíveis, } \\
\text { em quantidades adequadas, para as } \\
\text { gerações futuras, por meio da inovação, } \\
\text { buscando novos princípios, baseados nas } \\
\text { boas práticas, incluindo as da iniciativa } \\
\text { privada, para se adaptar aos novos rumos do } \\
\text { mercado, focando na sustentabilidade como } \\
\text { um todo e zelando pelo erário público. }\end{array}$ & $\begin{array}{l}\text { A iniciativa está em } \\
\text { implementação. Contudo, espera- } \\
\text { se também, dentre vários atributos } \\
\text { e lições, levar uma política dentro } \\
\text { do órgão destacando a } \\
\text { responsabilidade ambiental que } \\
\text { todos os servidores possuem, } \\
\text { evitando o desperdício, causando } \\
\text { um menor impacto socioambiental. }\end{array}$ \\
\hline $\begin{array}{l}\text { Ministério da Fazenda - } \\
\text { Economia de água } \\
\text { encanada e potável na } \\
\text { Controladoria Geral da } \\
\text { União. }\end{array}$ & $\begin{array}{l}\text { Para o órgão, compras sustentáveis estão } \\
\text { inseridas no campo das contratações } \\
\text { públicas, que representam a adequação da } \\
\text { contratação ao que se chama consumo } \\
\text { sustentável. Significa pensar a "proposta mais } \\
\text { vantajosa para a administração", levando-se } \\
\text { em conta não apenas o menor preço, mas o } \\
\text { custo benefício como um todo, considerando } \\
\text { a manutenção da vida no planeta e o bem- } \\
\text { estar social, por meio da inovação que é } \\
\text { repensar o modus operandi introduzindo } \\
\text { critérios sustentáveis. }\end{array}$ & 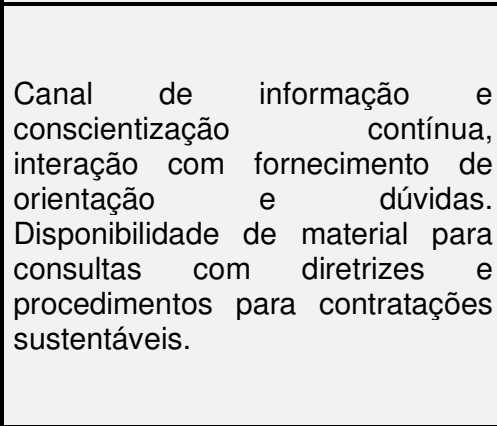 \\
\hline
\end{tabular}

Continua... 


\begin{tabular}{|c|c|c|}
\hline Instituição e Iniciativa & Contexto & Resultados \\
\hline $\begin{array}{l}\text { Ministério de Minas e } \\
\text { Energia - Boletim } \\
\text { Informativo "Faz Melhor" } \\
\text { e Orientações sobre as } \\
\text { Contratações } \\
\text { Sustentáveis do } \\
\text { Ministério da Fazenda. }\end{array}$ & $\begin{array}{l}\text { Para a instituição, compras sustentáveis são } \\
\text { instrumentos do Estado que influenciam as } \\
\text { atividades de produção e de consumo e que } \\
\text { podem contribuir significativamente com } \\
\text { iniciativas e ações que favoreçam e gerem } \\
\text { resultados satisfatórios de qualidade social, } \\
\text { equilíbrio ambiental e desenvolvimento } \\
\text { econômico para a promoção do } \\
\text { desenvolvimento nacional sustentável. }\end{array}$ & $\begin{array}{l}\text { O projeto está em implementação, } \\
\text { mas espera-se reduzir em } 5 \% \text { o } \\
\text { consumo de energia elétrica. }\end{array}$ \\
\hline $\begin{array}{l}\text { Universidade Federal de } \\
\text { Mato Grosso do Sul - } \\
\text { Campus Inteligente da } \\
\text { Universidade Federal de } \\
\text { Mato Grosso do Sul. }\end{array}$ & $\begin{array}{l}\text { A Instituição realiza compras diretamente e } \\
\text { os critérios de sustentabilidade na aquisição } \\
\text { de bens e serviços estão previstos no Plano } \\
\text { de Gestão de Logística Sustentável da } \\
\text { Fundação Universidade Federal de Mato } \\
\text { Grosso do Sul. As compras sustentáveis são } \\
\text { aquelas compras prioritárias na aquisição de } \\
\text { produtos e serviços mais sustentáveis } \\
\text { ambientalmente, observadas os critérios de } \\
\text { especificações técnicas e de preços, bem } \\
\text { como as ações de eficiência para evitar } \\
\text { compras desnecessárias, em que a inovação } \\
\text { busca atribuir ao processo licitatório métricas } \\
\text { capazes de privilegiar produtos e serviços } \\
\text { sustentáveis sem ferir os princípios da } \\
\text { administração pública. }\end{array}$ & $\begin{array}{l}\text { O Campus Inteligente permite que } \\
\text { a comunidade tenha acesso de } \\
\text { forma simples e rápida aos } \\
\text { indicadores de consumo da UFMS, } \\
\text { podendo comparar e avaliar a } \\
\text { eficácia dos programas de redução } \\
\text { no consumo. }\end{array}$ \\
\hline $\begin{array}{l}\text { Universidade Federal de } \\
\text { Santa Maria - Políticas } \\
\text { Nacionais de } \\
\text { Sustentabilidade } \\
\text { garantem eficiência } \\
\text { energética e logística } \\
\text { reversa na Universidade } \\
\text { Federal de Santa Maria. }\end{array}$ & $\begin{array}{l}\text { A Universidade Federal de Santa Maria } \\
\text { iniciou a inserção de critérios sustentáveis em } \\
\text { suas compras, visando à melhoria da } \\
\text { eficiência energética da instituição desde } \\
2010 \text {. Concomitantemente, em cumprimento } \\
\text { à Política Nacional de Resíduos Sólidos (Lei } \\
\text { 12.305/2010), a UFSM inseriu a política de } \\
\text { logística reversa nas compras públicas. }\end{array}$ & $\begin{array}{l}\text { A proporção de compras e } \\
\text { contratações sustentáveis da } \\
\text { UFSM é de aproximadamente } \\
10 \% \text {. Os setores envolvidos para o } \\
\text { cumprimento da meta são o } \\
\text { Departamento de Material e } \\
\text { Patrimônio e a Pró-Reitoria de } \\
\text { Infraestrutura. Além de diminuírem } \\
\text { o impacto ambiental da instituição, } \\
\text { essas iniciativas refletiram em } \\
\text { economia no consumo de energia } \\
\text { elétrica e com logística reversa, a } \\
\text { instituição também diminuiu seus } \\
\text { custos com a coleta de bens } \\
\text { inservíveis. }\end{array}$ \\
\hline $\begin{array}{lll}\text { Secretaria } & \text { Geral } & \text { da } \\
\text { Presidência } & & \text { da } \\
\text { República } & & \end{array}$ & $\begin{array}{l}\text { O órgão já possui um plano de capacitação } \\
\text { dos pregoeiros e servidores responsáveis } \\
\text { pela elaboração de Termo de Referência } \\
\text { sobre Licitações Sustentáveis. Além disso, } \\
\text { possui Evento anual que trata do tema e a } \\
\text { meta de conseguir } 80 \% \text { do seu almoxarifado } \\
\text { com produtos sustentáveis. }\end{array}$ & $\begin{array}{l}\text { Melhor entendimento dos } \\
\text { pregoeiros e dos servidores sobre } \\
\text { a inserção de critérios sustentáveis } \\
\text { nos processos de compras, sem } \\
\text { ônus para contratação de } \\
\text { palestrantes, considerando que } \\
\text { foram voluntários convidados de } \\
\text { outros órgãos. Quanto ao espaço } \\
\text { foi utilizado o Centro de } \\
\text { Capacitação da Presidência da } \\
\text { República. }\end{array}$ \\
\hline
\end{tabular}

Fonte: Adaptado de BRASIL, 2015. 


\section{Considerações finais}

Após a análise dos três manuais verificou-se que as licitações sustentáveis são instrumento para a mudança no padrão de consumo dos órgãos públicos, porém são aplicadas de forma isolada, pois exigem mudanças de comportamento, fato que implica na criação de programas de capacitação dos servidores envolvidos no processo, para que se transformem em agentes de mudança, através de uma reflexão crítica acerca dos impactos sociais e ambientais oriundos de suas atividades laborais.

O Programa Agenda Ambiental da Administração Pública (A3P) possui em sua estrutura um eixo temático, denominado sensibilização e capacitação que visa "criar e consolidar a consciência cidadã da responsabilidade socioambiental nos servidores [...] e contribuir para o desenvolvimento de competências institucionais e individuais" (CRESPO; MATOS; ABREU, 2009, p.45), no qual se pode destacar a importância da educação ambiental neste eixo, uma vez que a Educação Ambiental é um processo transformador que provoca mudança de hábitos e atitudes.

Conclui-se que a cultura institucional voltada para o desperdício, por meio do qual não se valoriza a racionalização do uso dos recursos financeiros e materiais, e a percepção do menor valor de aquisição são obstáculos para a inserção dos critérios de sustentabilidade ambiental nas licitações, exigindo dos gestores a adoção de programas de educação voltados para a gestão ambiental pública, buscando a sensibilização dos servidores em prol do consumo sustentável.

Assim, a solução apontada para a problemática em questão é a adesão ao Programa Agenda Ambiental da Administração Pública (A3P), pois diante de sua amplitude, é considerado um programa de gestão ambiental, uma vez que propõe a mudança da cultura institucional, ao incluir critérios sociais e ambientais na rotina administrativa, visando minimizar os impactos socioambientais através dos seus eixos temáticos (uso temático dos recursos naturais e bens públicos, gestão adequada dos resíduos sólidos, qualidade de vida no ambiente de trabalho, sensibilização e capacitação dos servidores e licitações sustentáveis) baseados na política dos 5 R's (repensar, reduzir, reaproveitar, reciclar e recusar).

\section{REFERÊNCIAS}

ASSOCIAÇÃO BRASILEIRA DE NORMAS TÉCNICAS (ABNT). NBR 16001:2004 - responsabilidade social - sistema de gestão - requisitos. Rio de Janeiro, 2004.

BARBIERI, J.C. Gestão ambiental empresarial: conceitos, modelos e instrumentos. 3 ed, São Paulo: Saraiva, 2011. 
BARCESSAT, L. Papel do estado brasileiro na ordem econômica e na defesa do meio ambiente: necessidade de opção por contratações públicas sustentáveis. In: SANTOS, M.G.; BARKI, T.V.P. (Coord.) Licitações e Contratações Públicas Sustentáveis. Belo Horizonte: Fórum, 2011. p. 67-81.

BETIOL, L.S. et al. Compra sustentável: a força do consumo público e empresarial para uma economia verde e inclusiva. São Paulo: FGV, 2012.

BORGES, A.M.C. Guia de inclusão de critérios de sustentabilidade nas contratações da Justiça do Trabalho. Brasília, 2012. Disponível em: $<$ http://www.csjt.jus.br/c/document library/get file?uuid=98bda927-99d0-46cfa193-0863d3f13c3a\&groupld=955023> Acesso em 12/04/2014.

BRASIL. Constituição da República Federativa do Brasil de 1988. Disponível

em: $<$ http://www.planalto.gov.br/ccivil 03/constituicao/constituicaocompilado.htm>. Acesso em: 20/03/2013.

BRASIL. Lei $n^{\circ}$ 8666, de 21 de junho de 1993. Regulamenta o art. 37, inciso $X X I$, da Constituição Federal, institui normas para licitações e contratos da Administração Pública e dá outras providências. Brasília, 21 jun. 1993. Disponível em: http://www.planalto.gov.br/ccivil 03/leis/l8666cons.htm. Acesso em: 10/02/2014.

BRASIL. Lei $\mathbf{N}^{\circ}$ 9.795, de 27 de abril de 1999.Dispõe sobre a educação ambiental, institui a Política Nacional de Educação Ambiental e dá outras providências. Disponível em: http://www.planalto.gov.br/ccivil 03/leis/19795.htm. Acesso em: 10/02/2014.

BRASIL. Instrução Normativa № 01, de 19 de janeiro de 2010. Dispõe sobre a inserção de critérios de sustentabilidade ambiental na aquisição de bens, contratação de serviços ou obras pela Administração Pública Federal direta, autárquica e fundacional e dá outras providências. Brasília, 19 jan. 2010 a. Disponível em: http://www.comprasnet.gov.br/legislacao/legislacaoDetalhe.asp?ctdCod=295. Acesso em: 02/08/2013.

BRASIL. Lei no 12.349 de 15 de dezembro de 2010. Altera as leis no 8.666, de 21 de junho de 1993, 8.958, de 20 de dezembro de 1994, e 10.973; de 2 de dezembro de 2004; e revoga o $\S 1^{\circ}$ do art. 2을 Lei $n^{\circ} 11.273$, de 6 de fevereiro de 2006. Brasília, 15 dez. 2010 d. Disponível em: http://www.planalto.gov.br/ccivil 03/ Ato2007-2010/2010/Lei/L12349.htm. Acesso em: 23/03/2013.

BRASIL. Ministério do Planejamento, Orçamento e Gestão. Contratações Públicas Sustentáveis. Disponível em: http://cpsustentaveis.planejamento.gov.br/boas-praticas. Acesso em 25/02/2015. 
CHIAVENATO, I. Recursos Humanos: o capital humano das organizações. 8 ed. São Paulo: Atlas, 2006.

COMISSÃO EUROPÉIA. Comprar Ecológico! Manual de contratos públicos ecológicos. Luxemburgo: Serviço das Publicações Oficiais das Comunidades Europeias. 2005.

COMISSÃO MUNDIAL SOBRE MEIO AMBIENTE E DESENVOLVIMENTO. Nosso futuro comum. 2 ed. Rio de Janeiro: FGV, 1991

CRESPO, S.B.S.; MATOS, K.M.; ABREU, G.V. Manual da agenda ambiental na Administração Pública - A3P. Ministério do Meio Ambiente - MMA. 5aㅡ ed. Brasília: 2009.

FERREIRA, D. A licitação pública na Brasil e sua nova finalidade legal: a promoção do desenvolvimento nacional sustentável. Belo Horizonte: Fórum, 2012.

FURRIELA, R.B. Educação para o consumo sustentável. In: Ciclo de palestras sobre meio ambiente. Brasília: MEC/SEF/COEA, 2001. p. 47-55.

GIL. A.C. Métodos e técnicas de pesquisa social. 5 ed. São Paulo: Atlas, 1999.

GUIMARÃES, E.S. Manual de planejamento das licitações públicas. Curitiba: Juruá, 2012.b

GUNTHER, E.; SCHEIBE, L. The Hurdles Analysis: A method to identify and analyse hurdles for green procurement in municipalities. Dresdner Beiträge zur Betriebswirtschaftslehre, Dresden. no 80/04. p. 1-49.

ISLAM Md, M.; SIWAR, C. A Comparative Study of Public Sector Sustainable Procurement Practices, Opportunities and Barriers. In: International Review of Business Research Papers .Melbourne, vol. 9. no. 3. March 2013 Issue. Pp. $62-84$.

LEFF, E. Pensar a complexidade ambiental. In: LEFF, E.(Coord.) A complexidade ambiental. 2 ed. São Paulo: Cortez, 2010.

MARIN, A.A. Pesquisa em educação ambiental e percepção ambiental. Pesquisa em educação ambiental. 2008. vol.3 (1), p. 203-222.

MENEGUZZI, R.M. Conceito de Licitação Sustentável. In: BARKI, T.V.P.; SANTOS, M.G. (Coord.) Licitações e Contratações Públicas Sustentáveis. Belo Horizonte: Fórum, 2011. p. 19-38.

MOREIRA, M.F.; VARGAS, E.R. O papel das compras governamentais na indução de inovações. Contabilidade, Gestão e Governança. v. 12 ํo 2 p. 35 $-43,2009$. 
PELICIONI, M.C.F.; PHILIPPI JR, A. Bases políticas, conceituais, filosóficas e ideológicas da educação ambiental. In: PELICIONI, M.C.F.; PHILIPPI JR, A. (Coord.). Educação ambiental e sustentabilidade. Barueri, SP: Manole, 2005 (Coleção Ambiental; 3).

PORTILHO, $F$ Consumo sustentável: limites $e$ possibilidades de ambientalização e politização das práticas de consumo. Cadernos EBAPE.BR. 2005.p 1-12.

SANTOS, R.S. et al. Guia de compras públicas sustentáveis para a Administração Federal. Disponível em: $<$ http://cpsustentaveis.planejamento.gov.br/wp-

content/uploads/2010/06/Cartilha.pdf> Acesso em: 12/02/2014.

SANTOS, M.G. Poder normativo nas licitações sustentáveis In: SANTOS, M. G.; BARKI, T.V.P. (Coord.) Licitações e Contratações Públicas Sustentáveis. Belo Horizonte: Fórum, 2011. p. 153-173.

SEIFFERT. M.E.B. Gestão Ambiental: instrumentos, esferas de ação e educação ambiental. 2 ed. São Paulo: Atlas, 2011.

SILVA, M.E.; BALBINO, D.P.; GÓMEZ, C.P. Consumo Sustentável na base da pirâmide: definindo papéis e obrigações para a efetivação do desenvolvimento sustentável. Revista de Gestão Social e Ambiental - RGSA, São Paulo, v. 5, no 2, p.18-33, Mai./Ago. 2011

SIMÕES, C.P. Responsabilidade social e cidadania: conceitos e ferramentas. Brasília, 2008. Disponível em: http://www.sfiec.org.br/portalv2/sites/sesiv3/files/files/Livro\%20de\%20Resp.pdf Acesso em: 26/07/2013.

VARGAS, L.C.; MACEDO, S.R.K. Educação ambiental empresarial: reflexão sobre os desafios da atuação no contexto escolar. Ambiente e Educação. vol. 15 (2), 2010. 209-228.

WALKER, $H$. et al. Sustainable procurement: an international policy analysis of 30 oecd countries. Disponível em: <http://www.ippa.org/IPPC5/Proceedings/Part5/PAPER5-10.pdf> Acesso em $11 / 02 / 2014$. 